\title{
Avaliação da qualidade das obturações endodônticas realizadas por estudantes de graduação
}

\author{
Evaluation of the quality of the root canal fillings accomplished by undergraduate students
}

Rubens Girardi Freitas', Deborah Meirelles Cogo², Patrícia Maria Polli Kopper³, Régis Burmeister Santos ${ }^{4}$, Fabiana Soares Grecca ${ }^{5}$

\section{Resumo}

O objetivo deste estudo foi avaliar a qualidade das obturações dos canais radiculares realizados por estudantes de graduação em Odontologia. A amostra foi constituída por 156 canais radiculares obturados e analisados através de radiografias periapicais. Compuseram a análise dentes uni e multirradiculares com tratamento endodôntico concluído há pelo menos dois anos. As radiografias foram avaliadas por três endodontistas calibrados. A condição periapical foi classificada como tendo ou não presença de lesão. Já a qualidade da obturação radicular foi determinada através de dois parâmetros: a relação do comprimento da obturação com a extensão do canal e a qualidade da condensação do material obturador. Os resultados mostraram que 75 canais $(48 \%)$ foram classificados como tendo qualidade de tratamento satisfatória. Em 101 canais radiculares $(64,5 \%)$, observou-se a presença de lâmina dura, caracterizando, portanto, uma condição periapical normal.

Palavras-chave: Proservação; Qualidade do tratamento endodôntico; Condição periapical; Estudantes.

\begin{abstract}
The aim of this study was to evaluate the periapical condition and the quality of root canal fillings accomplished by undergraduate students. The sample was constituted by 156 filled root canals of one-root and multi-root teeth whose treatment conclusion had happened at least two years before. Periapical radiographies were evaluated by three calibrated endodontists. The periapical condition was classified as having or not having periapical lesion. The quality of the root filling was determined using two parameters: the relationship between the length of the filling with the extension of the canal and the quality of the condensation of the filling material. The results showed that $75(48 \%)$ root canals were classified as possessing satisfactory treatment quality. In 101 root canals (64.5\%), the presence of hard layer was observed, characterizing a normal periapical condition.
\end{abstract}

Keywords: Proservation; Quality of the endodontic treatment; Periapical condition; Students.

\section{Introdução}

A obturação do canal radicular consiste no seu preenchimento de forma completa a fim de impedir a entrada de bactérias. É a consagração do tratamento, pois perpetua o estado de desinfecção conseguido durante o preparo químico-mecânico.

A obtenção do adequado selamento apical do canal radicular ainda é considerado um fator primordial no tratamento, apesar dos recentes estudos de infiltração bacteriana via selamento coronário (SIQUEIRA et al., 2000). O sucesso do tratamento endodôntico é avaliado com base na análise radiográfica e na ausência de sinais ou sintomas clínicos durante a proservação do dente (BENENATI; KHAJOTIA, 2002).

A maioria dos estudos epidemiológicos endodônticos relata alta prevalência de periodontite apical associada a dentes com canais radiculares que apresentavam obturações inadequadas
${ }_{1}^{1}$ Aluno do Curso de Odontologia da UFRGS.

${ }^{2}$ Aluna do Curso de Especialização do CEOM - Centro de Estudos Odontológicos Meridional.

${ }^{3}$ Doutora em Clínica Odontológica pela UFRGS, Professora-Adjunta da Faculdade de Odontologia da PUC-RS.

${ }^{4}$ Professor Titular em Clínica Odontológica da Faculdade de Odontologia da UFRGS.

${ }^{5}$ Professor-Adjunto em Clínica Odontológica da Faculdade de Odontologia da UFRGS.

Correspondência: Fabiana Soares Grecca

Endereço: Rua Ramiro Barcelos, 2492 - 90035-003 - Porto Alegre - RS Fone: 5133085191

E-mail: fakera@terra.com.br

(KIRKEVANG et al., 2000; DE MOOR et al., 2000; KIRKEVANG; WENZEL, 2003; KABAK; ABBOTT, 2005).

A presença de lesão periapical nem sempre indica fracasso do tratamento endodôntico porque o reparo ainda pode estar ocorrendo. Por esta razão, devemos ter cuidado ao avaliar apenas uma imagem radiográfica (LOFTUS; KEATING; MCCARTAN, 2005).

A literatura apresenta estudos que correlacionam o sucesso e o fracasso dos tratamentos endodônticos à qualidade da obturação, seu limite apical, presença prévia e extensão de lesão periapical, infiltração apical e coronária, complexidade anatômica e presença de lesão de cárie após tratamento (TRAVASSOS; CALDAS JUNIOR; ALBUQUERQUE, 2003).

Esta pesquisa teve como objetivo avaliar a qualidade dos tratamentos endodônticos e a condição periapical dos dentes tratados por alunos de graduação da Faculdade de Odontologia da UFRGS, através da observação radiográfica de tratamentos realizados entre os anos de 2000 e 2004.

\section{Metodologia}

O presente estudo foi aprovado pelo comitê de ética e pesquisa da Faculdade de Odontologia da Universidade Federal do Rio Grande do Sul (FOUFRGS). Foram selecionados prontuários de 100 pacientes da FOUFRGS com canais radiculares tratados na disciplina de Endodontia entre os anos de 2000 a 2004.

A disciplina preconiza a técnica escalonada de preparo e obturação pela técnica da condensação lateral, utilizando cones de guta-percha e cimento Endofill (Dentsply Maillefer, Petrópolis, Rio de Janeiro).

Convidados a realizar uma radiografia de proservação do caso, compareceram 86 pacientes que assinaram o termo de consentimento informado. A amostra foi composta por 97 dentes e 156 canais.

\section{Obtenção das radiografias}

Os dentes foram radiografados com filmes radiográficos Insight $\mathrm{n}^{\circ} .2$ (Kodak, Rochester, EUA) e aparelho de raios $\mathrm{X}$ de $10 \mathrm{~mA}$, e $70 \mathrm{KvP}$ (Dabi-Atlante, Ribeirão Preto, SP, Brasil) com exposição de 0,4 segundos. $O$ processamento radiográfico se deu pelo método temperatura/tempo. Após a secagem, a radiografia foi 
montada em uma moldura de cartolina com identificação do paciente/dente, para posterior avaliação.

Nos casos de dentes multirradiculares em que os canais radiculares estavam sobrepostos, utilizou-se a técnica de dissociação radiográfica para possibilitar a visualização.

\section{Critérios de avaliação}

Os critérios de avaliação foram os seguintes:

- Condição da região periapical: ausência de lesão periapical (imagem mostrando integridade da lâmina dura na região); presença de lesão periapical (imagem mostrando rompimento da lâmina dura associada à área radiolúcida);

- Limite apical da obturação: subobturação quando a obturação ficou mais de $2 \mathrm{~mm}$ aquém do vértice radiográfico. A obturação foi considerada adequada quando ficou entre 1 e $2 \mathrm{~mm}$ aquém do vértice radiográfico. A obturação total correspondeu àquela que ficou ao nível do vértice radiográfico, preenchendo completamente o canal radicular. Foi considerada como sobreobturação quando o material obturador ultrapassou o vértice radiográfico;

- Condensação do material obturador: adequada quando não foram visualizados espaços vazios dentro da massa obturadora; inadequada quando se observavam falhas no âmago da obturação;

- Qualidade do tratamento: satisfatório quando a imagem radiográfica mostrou adequada condensação do material obturador, preenchendo toda a extensão do canal e situando-se 1 a $2 \mathrm{~mm}$ ou ao nível do vértice apical radiográfico (obturação total); insatisfatório quando a imagem radiográfica mostrava áreas radiolúcidas no interior da massa obturadora, mesmo que o limite fosse o CDC (cementodentina-canal) ou o vértice; e, quando o canal apresentava-se subobturado ou sobreobturado, independentemente do aspecto radiográfico da obturação.

- Condição clínica do dente: foi também analisada a condição restauradora em que o dente se encontrava (aberto, restauração provisória ou restauração definitiva).

As imagens radiográficas foram examinadas por três endodontistas, previamente calibrados, atingindo Kappa intraexaminador de 0,9 e inter examinadores de 0,7.

Os pacientes que apresentaram tratamentos considerados insatisfatórios foram encaminhados para o retratamento na FOUFRGS.

A análise dos resultados foi feita de forma descritiva utilizando-se os valores percentuais.

\section{Resultados}

Na Tabela 1 observa-se a distribuição da amostra de acordo com o grupo dental e número de canais.

O Gráfico 1 mostra o limite apical da obturação e o Gráfico 2 a condição restauradora em que o dente se encontrava no momento da proservação (aberto, restauração provisória ou restauração definitiva).

Com relação à condição da região periapical, 35,5\% dos casos apresentavam imagem compatível com lesão periapical, isto é, imagem mostrando rompimento da lâmina dura associada a área radiolúcida e $64,5 \%$ apresentavam ausência de lesão periapical.

A condensação do material obturador foi considerada adequada em $69 \%$ dos casos e inadequada em $31 \%$, em que se observou falhas no âmago da obturação.
Com relação à qualidade do tratamento endodôntico, 52\% dos casos foram considerados insatisfatórios, ou seja, a imagem radiográfica mostrava áreas radiolúcidas no interior da massa obturadora, mesmo que o limite fosse o CDC (cemento-dentina-canal) ou o vértice; ou o canal apresentava-se subobturado ou sobreobturado, independentemente do aspecto radiográfico da obturação. Foram considerados satisfatórios $48 \%$ dos casos.

Tabela 1. Distribuição de acordo com o grupo dental e o número de canais.

\begin{tabular}{cccccc}
\hline & Maxila & \multicolumn{4}{c}{ Mandíbula } \\
\hline & $\begin{array}{c}n \\
\text { (dentes) }\end{array}$ & $\begin{array}{c}n \\
\text { (canais) }\end{array}$ & & $\begin{array}{c}n \\
\text { (dentes) }\end{array}$ & $\begin{array}{c}\boldsymbol{n} \\
\text { (canais) }\end{array}$ \\
\hline Incisivo Central & 13 & 13 & Incisivo Central & 2 & 2 \\
Incisivo Lateral & 9 & 9 & Incisivo Lateral & 3 & 3 \\
Canino & 9 & 9 & Canino & 3 & 3 \\
$1^{\circ}$ Pré-Molar & 11 & 22 & $1^{\circ}$ Pré-Molar & 6 & 6 \\
$2^{\circ}$ Pré-Molar & 10 & 10 & $2^{\circ}$ Pré-Molar & 6 & 6 \\
$1^{\circ}$ Molar & 6 & 16 & $1^{\circ}$ Molar & 6 & 18 \\
$2^{\circ}$ Molar & 4 & 12 & $2^{\circ}$ Molar & 8 & 24 \\
$3^{\circ}$ Molar & 1 & 3 & $3^{\circ}$ Molar & 0 & 0 \\
\hline Total & 63 & 94 & Total & 34 & 62 \\
\hline
\end{tabular}

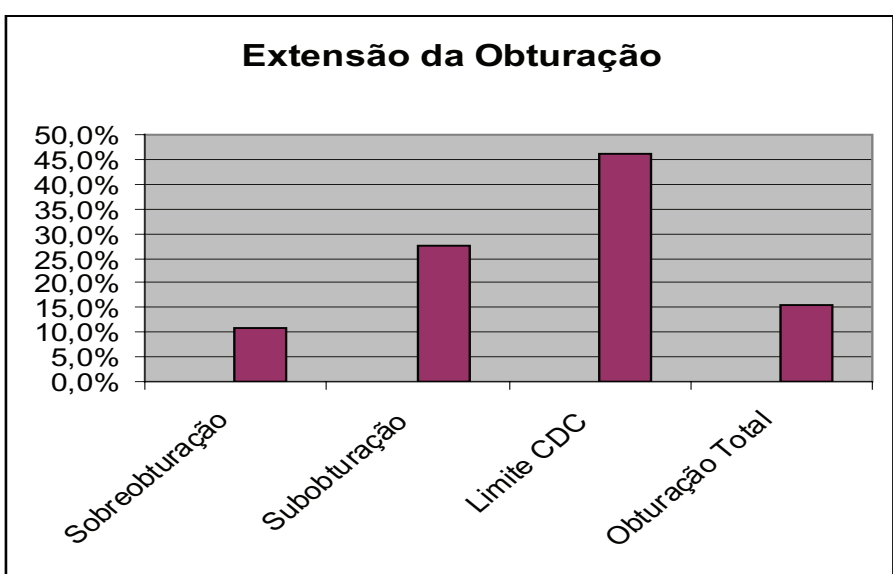

Gráfico 1. Limite apical de obturação.

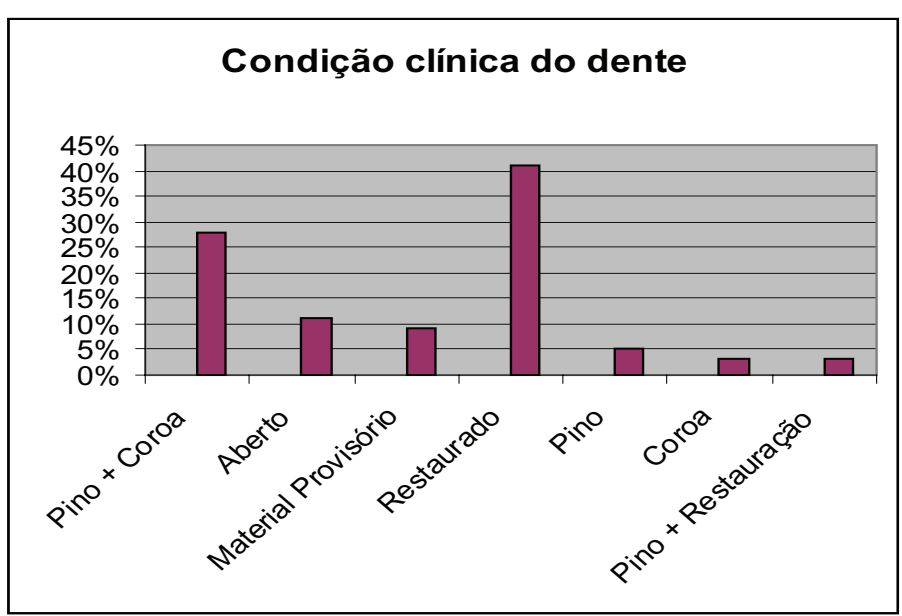

Gráfico 2. Condição clínica do dente. 


\section{Discussão}

A avaliação da qualidade dos tratamentos incluídos neste estudo foi realizada por meio de radiografias periapicais por ser um dos modos de analisar com detalhes e alguma precisão a terapia endodôntica e suas consequências.

A periodontite apical é diagnosticada por critérios clínicos e radiográficos sendo que a radiografia é o recurso de eleição para o seu diagnóstico (LOFTUS; KEATING; MCCARTAN, 2005). Dos canais radiculares avaliados, 35,5\% apresentavam imagem compatível com lesão periapical, dado insuficiente para estabelecer o fracasso do tratamento sem o conhecimento da evolução clínica dos casos. Como não foi possível identificar sua regressão ou progressão, a situação apical não influenciou na classificação da qualidade dos tratamentos endodônticos, apesar de terem sido selecionados pacientes com tratamentos realizados há mais de dois anos.

O limite apical da obturação ideal deve ser o mais próximo possível do limite CDC, restringindo-se ao canal dentinário. Neste estudo, $61,5 \%$ dos canais apresentavam-se obturados em um limite adequado, ou seja, limite CDC ou obturação total. Quanto a este quesito, Lupi-Pegurier et al. (2002), ao avaliarem 1429 casos realizados por profissionais, encontraram um índice de $38,7 \%$. Dugas et al. (2003), em 383 casos avaliados, verificaram que $58 \%$ apresentaram limite de obturação considerado adequado.

Canais radiculares sub ou sobreobturados têm demonstrado um prognóstico menos favorável (CHEN et al., 2007; DUGAS et al., 2003). No presente estudo, $27,5 \%$ foram subobturados e $11 \%$ sobreobturados, demonstrando a possibilidade de um prognóstico insatisfatório para a saúde dos tecidos periapicais. Chen et al. (2007) verificaram que apenas $26 \%$ dos dentes por eles avaliados estavam adequadamente obturados, e $35,5 \%$ apresentavam lesão periapical.

No que diz respeito à condensação lateral, Dugas et al. (2003) consideraram que a falha nesta etapa do tratamento do canal pode representar uma possibilidade 2,7 vezes maior de desenvolvimento de uma periodontite apical. O percentual de falhas na condensação lateral aqui observado foi de $31 \%$, índice menor do que os $41,1 \%$ relatados por Lupi-Pegurier et al. (2002).

Ao comparar-se o resultado global da qualidade dos tratamentos endodônticos levantados em vários estudos, constatou-se que não há diferenças marcantes na incidência de bons ou maus, satisfatórios ou não. Como exemplo, pode-se citar os resultados publicados por Siqueira et al. (2005), com $56,9 \%$ de casos considerados satisfatórios, por Lupi-Pegurier et al. (2002), demonstrando $32 \%$ de obturações adequadas e pelo presente estudo, em que $48 \%$ dos casos foram classificados como satisfatórios. O que pode ser discutido é a dificuldade de definir um padrão do método de avaliação e os critérios para estabelecer os parâmetros de qualidade, além do equilíbrio da avaliação intra e interexaminadores. Tal dificuldade foi expressa no resultado obtido na pesquisa de Sjögren et al. (1997), que obteve um índice de sucesso de 95\%.

Destaca-se que, na presente investigação, foi considerado insatisfatório o tratamento que apresentasse a obturação do canal com limite apical adequado e condensação lateral deficiente, assim como condensação lateral de boa qualidade e limite apical aquém ou além do local aceitável para a junção cemento-dentinária. Critérios que, no nosso entender, demonstram a preocupação com o rigor na avaliação global dos tratamentos.

Quando avaliados à luz do rigor acadêmico, os tratamentos endodônticos não mostram índice de qualidade além do mediano. Esse fato denota a dificuldade da técnica endodôntica, principalmente quando executada por acadêmicos dos primeiros semestres de disciplinas clínicas.

Tronstad et al. (2000), encontraram que a qualidade da restauração coronária é de grande importância quando combinada também com um tratamento endodôntico adequado. Siqueira et al. (2000) demonstraram que dentes com obturação endodôntica adequada e ausência de restaurações mostraram índice de sucesso $10 \%$ maior do que aqueles com obturação inadequada e restauração adequada. Isso mostra que a qualidade do tratamento endodôntico é um fator importante em relação à saúde do tecido periapical. No presente estudo, $80 \%$ dos casos apresentavam restauração definitiva, demonstrando o cuidado com o pós-tratamento endodôntico.

\section{Conclusão}

Nas condições em que o estudo foi realizado, pode-se concluir que $48 \%$ dos canais foram classificados como tendo qualidade de tratamento satisfatória e em $64,5 \%$ observou-se a presença de lâmina dura, caracterizando, portanto, uma condição periapical normal.

\section{Referências}

BENENATI, F. W.; KHAJOTIA, S. S. A Radiographic Recall Evaluation of 894 Endodontic Cases Treated in a Dental School Setting. J. Endod., New York, v. 28, n. 5, p. 391-395, May 2002.

CHEN, C. Y. et al. Prevalence and Quality of Endodontic Treatment in the Northern Manhattan Elderly. J. Endod., New York, v. 33, n. 3, p. 230-234, Mar. 2007.

DE MOOR, R. J. G. et al. Periapical Health Related to the Quality of Root Canal Treatment in a Belgian Population. Int. Endod. J., Oxford, v. 33, n. 2, p. 113-120, Mar. 2000.

DUGAS, N. N. et al. Periapical Health and Treatment Quality Assessment of Root-Filled Teeth in Two Canadian Populations. Int. Endod. J., Oxford, v. 36, n. 3, p. 181-192, Mar. 2003.

GREEN, M. S. et al. Radiographic and Histologic Periapical Findings of Root Canal Treated Teeth in Cadaver. Oral Surg. Oral Med. Oral Pathol. Oral Radiol. Endod., St. Louis, v. 83, n. 6, p. 707-11, June 1997.

KABAK, Y; ABBOTT, P. V. Prevalence of Apical Periodontitis and the Quality of Endodontic Treatment in an Adult Belarusian Population. Int. Endod. J., Oxford, v. 38, n. 4, p. 238-245, Apr. 2005.

KIRKEVANG, L. L. et al. Periapical Status and Quality of Root Fllings and Coronal Restorations in a Danish Population. Int. Endod. J., Oxford, v. 33, n. 6, p. 509-515, Nov. 2000.

KIRKEVANG, L. L.; WENZEL, A. Risk Indicators for Apical Periodontitis. Community Dent. Oral Epidemiol., Copenhagen, v. 31, n. 1, p. 59-67, Feb. 2003.

LOFTUS, J. J.; KEATING A. P.; MCCARTAN, B. E. Periapical Status and Quality of Endodontic Treatment in an Adult Irish Population. Int. Endod. J., Oxford, v. 38, n. 2, p. 81-86, Feb. 2005.

LUPI-PEGURIER, L. et al. Periapical Status, Prevalence and Quality of Endodontic Treatment in an Adult French Population. Int. Endod. J., Oxford, v. 35, n. 8, p. 690-697, Aug. 2002.

SIQUEIRA, J. F. et al. Bacterial Leakage in Coronally Unsealed Root Canals Obturated with 3 Different Techniques. Oral Surg. Oral Med. Oral Pathol. Oral Radiol. Endod., St. Louis, v. 90, n. 5, p. 647-650, Nov. 2000. 
SJÖGREN, U. et al. Influence of Infection at the Time of Root Flling on the Outcome of Endodontic Treatment of Teeth with Apical Periodontitis. Int. Endod. J., Oxford, v. 30, n. 5, p. 297-306, Sept. 1997.

TRAVASSOS, R. M. C.; CALDAS JUNIOR, A. F.; ALBUQUERQUE, D. S. Cohort Study of Endodontic Therapy Success. Braz. Dent. J., Ribeirão Preto, v. 14, n. 2, p. 109-113, 2003.

TRONSTAD, L. et al. Influence of Coronal Restorations on the Periapical Health of Endodontically Treated Teeth. Endod. Dent. Traumatol., Copenhagen, v. 16, n. 5, p. 218-221, Oct. 2000. 